Article

\title{
Feasibility, Acceptability, and Clinical Significance of a Dyadic, Web-Based, Psychosocial and Physical Activity Self-Management Program (TEMPO) Tailored to the Needs of Men with Prostate Cancer and Their Caregivers: A Multi-Center Randomized Pilot Trial
}

\author{
Sylvie D. Lambert ${ }^{1,2}, * \mathbb{1}$, Lindsay R. Duncan ${ }^{3}$, S. Nicole Culos-Reed ${ }^{4,5}$, Laura Hallward ${ }^{3}$, Celestia S. Higano ${ }^{6}$, \\ Ekaterina Loban 1,7®), Anne Katz ${ }^{8}$, Manon De Raad ${ }^{1}$, Janet Ellis ${ }^{9}$, Melissa B. Korman ${ }^{10}{ }^{(1)}$, Carly Sears ${ }^{11}$, \\ Cindy Ibberson ${ }^{1}$, Lauren Walker ${ }^{12}$, Eric Belzile ${ }^{1}$, Paramita Saha-Chaudhuri ${ }^{13}$, Helen McTaggart-Cowan ${ }^{14}$ \\ and Stuart Peacock ${ }^{14}$
}

check for

updates

Citation: Lambert, S.D.; Duncan, L.R.; Culos-Reed, S.N.; Hallward, L.; Higano, C.S.; Loban, E.; Katz, A.; De Raad, M.; Ellis, J.; Korman, M.B.; et al Feasibility, Acceptability, and Clinical Significance of a Dyadic, Web-Based, Psychosocial and Physical Activity Self-Management Program (TEMPO) Tailored to the Needs of Men with Prostate Cancer and Their Caregivers: A Multi-Center Randomized Pilot Trial. Curr. Oncol. 2022, 29, 785-804 https://doi.org/10.3390/ curroncol29020067

Received: 27 November 2021 Accepted: 18 January 2022 Published: 1 February 2022

Publisher's Note: MDPI stays neutral with regard to jurisdictional claims in published maps and institutional affiliations.

Copyright: (C) 2022 by the authors. Licensee MDPI, Basel, Switzerland. This article is an open access article distributed under the terms and conditions of the Creative Commons Attribution (CC BY) license (https:/ / creativecommons.org/licenses/by/ $4.0 /)$.
1 St. Mary's Research Centre, Montreal, QC H3T 1M5, Canada; ekaterina.loban@mail.mcgill.ca (E.L.); manon.deraad@ssss.gouv.qc.ca (M.D.R.); cindy.ibberson@ssss.gouv.qc.ca (C.I.); eric.belzile@ssss.gouv.qc.ca (E.B.)

2 Ingram School of Nursing, McGill University, Montreal, QC H3A 0G4, Canada

3 Department of Kinesiology and Physical Education, McGill University, Montreal, QC H3A 0G4, Canada; lindsay.duncan@mcgill.ca (L.R.D.); laura.hallward@mail.mcgill.ca (L.H.)

4 Health and Wellness Lab, Thrive Centre, Faculty of Kinesiology, Department of Oncology, Cumming School of Medicine, University of Calgary, Calgary, AB T2N 1N4, Canada; nculosre@ucalgary.ca

5 Department of Psychosocial Resources, Tom Baker Cancer Centre, Calgary, AB T2N 4N2, Canada

6 Vancouver Prostate Centre, Prostate Cancer Supportive Care Program, Department of Urologic Sciences, University of British Columbia, Vancouver, BC V6T 1Z4, Canada; madronaoncology@gmail.com

7 Department of Family Medicine, McGill University, Montreal, QC H3S 1Z1, Canada

8 Cancer Care Manitoba, Winnipeg, MB R3E 0V9, Canada; drannekatz@gmail.com

9 Odette Cancer Centre, Sunnybrook Health Sciences Centre, Toronto, ON M4N 3M5, Canada; janet.ellis@sunnybrook.ca

10 Sunnybrook, Research Institute Department of Evaluative Clinical Sciences, Toronto, ON M5S 1A1, Canada; melissa.korman@sri.utoronto.ca

11 University of Calgary, Calgary, AB T2N 1N4, Canada; carly.sears@albertahealthservices.ca

12 Department of Oncology \& Psychology, University of Calgary, Calgary, AB T2P 4Z6, Canada; lauren.walker@albertahealthservices.ca

13 Department of Mathematics and Statistics, University of Vermont, Burlington, VT 05405, USA; paramita.saha-chaudhuri@uvm.edu

14 Canadian Centre for Applied Research in Cancer Control, Cancer Control Research, BC Cancer, Faculty of Health Sciences, Simon Fraser University, Burnaby, BC V5A 1S6, Canada; hcowan@bccrc.ca (H.M.-C.); speacock@bccrc.ca (S.P.)

* Correspondence: sylvie.lambert@mcgill.ca

\begin{abstract}
Background: Prostate cancer is the most common cancer diagnosis among men. Family caregivers (often female spouses) play a key role in ensuring patients' needs are met, frequently assuming their role with no formal training, which can contribute to a high burden. The purpose of this study was to pilot TEMPO—-the first dyadic, Tailored, wEb-based, psychosocial and physical activity self-Management PrOgram for men with prostate cancer and their caregivers. Methods: 49 men with prostate cancer and their caregivers were randomized to TEMPO or usual care. Baseline and follow-up questionnaires were completed to assess feasibility, acceptability, and clinical significance. A priori benchmarks for these outcomes were set. Thirteen exit interviews were conducted to further explore acceptability. Results: Feasibility benchmarks were met with the exception for recruitment with on average 6.1 dyads recruited/month (benchmark: 8 dyads/month). Benchmarks of acceptability focused on attrition $(<25 \%)$ and system usability, which were met. Using the strict criteria for adherence of $100 \%$ of the module viewed and participants spending at least 15 min on the module, $45 \%$ of participants were adherent. The clinical significance on anxiety and quality of life was supported for caregivers, and mostly supported for the men with prostate cancer. Conclusion: This pilot trial was successful, with minor modifications needed prior to a large trial.
\end{abstract}


Keywords: self-management; prostate cancer; caregivers; behavior change; physical activity; e-Health interventions; dyadic interventions; psychosocial needs; dyads; pilot study

\section{Introduction}

Prostate cancer is the most common cancer among men [1]. Despite increasing survival rates, prostate cancer and its treatment remain a major life stressor [2,3], and confront men with many physical symptoms (e.g., urinary incontinence, bowel dysfunction, and sexual dysfunction) [4,5] and psychosocial challenges (e.g., anxiety, depression, and fatigue) [6-8] These challenges often remain poorly managed, resulting in impaired functioning and lower quality of life than the general population [9].

With prostate cancer care mainly delivered as outpatient treatment, most men rely on their partners or family members (referred to as caregivers) for support in coping with daily cancer challenges $[10,11]$. Caregivers are (more than ever) tasked with complex illness management roles (e.g., managing side effects) [12], usually with little formal training, potentially leading to inefficient trial and error. Although caregiver support positively impacts patients' health outcomes $[13,14]$ and reduces demands on the health care system [12], the impact on the caregiver is significant. Caregivers report clinically significant anxiety [15], depression [16], fatigue [17], and deteriorating or lower physical health than the population norm [18]. As the health of caregivers deteriorates and they are less able to provide support, patients' health is adversely affected [19].

Given the challenges faced by both men with prostate cancer and their caregivers, there is a need to support the patient-caregiver dyad in negotiating cancer challenges and optimizing their health outcomes. In fact, dyadic interventions are found to be more efficacious than patient-only or caregiver-only interventions, because of the shared learning that occurs and the interdependency of patients' and caregivers' coping and health outcomes [20]. These interventions, mostly based in principles of psychoeducation and self-management, focus on teaching the skills needed to address the challenges of illness and build confidence for enacting those skills to enhance wellness [21,22]. Learning these self-management skills involves changing behaviors by using self-monitoring, goal setting, information seeking, decision making, and action planning [23]. Most of these interventions are delivered by trained health care professionals, in clinic settings or home-visits, over the course of weeks to months. Despite their efficacy [20,24-26], as these interventions are resource- and cost-intensive, they are rarely implemented into real-world settings [27]. Therefore, more cost-effective delivery formats are needed.

Web-based interventions can provide efficacious, cost-effective, and tailored selfmanagement support [28]. FOCUS [29] (psycho-education intervention) and CARES [30] (self-management intervention) are two web-based interventions for cancer patients and caregivers that demonstrate feasibility and acceptability evidence for the use of web-based delivery of dyadic interventions. However, limitations of these interventions include (a) the content is pre-determined and not tailored to users' needs, (b) key components of self-management (e.g., goal setting) are neglected, and/or (c) the focus is often on mental health and not physical health. To address these limitations, we developed TEMPO, the first dyadic, Tailored, wEb-based, psychosocial and physical activity self-Management PrOgram specifically for men with prostate cancer and their caregivers.

\section{TEMPO}

TEMPO is an evidence-informed program designed for men with prostate cancer and their caregivers (as a dyad) to learn self-management skills based on their priority needs, set goals together, and build confidence to address and manage their needs. Alongside the psychosocial self-management content (e.g., managing stress, symptoms), TEMPO supports the use of physical activity as a self-management strategy to enhance overall physical (and mental) health. 
Three theoretical frameworks guided the development of TEMPO:

1. The Stress and Coping Framework [31], which assumes those who actively cope with cancer challenges report less anxiety [32].

2. The Framework of Dyadic Coping [33] posits positive patient-caregiver coping leads to enhanced outcomes for both members of the dyad [34].

3. Self-Efficacy Theory [35] whereby strategies to enhance self-efficacy were built into $T E M P O$ such as behavioral goals, behavior modeling from others, and verbal persuasion.

See Table 1 for a complete description of TEMPO following the TIDieR guideline [36]. Briefly, TEMPO is a 10-week, web-based intervention, where men with prostate cancer and their caregivers are guided through five modules: needs assessment, goal setting and action planning based on most pressing needs, coping planning, sources of support and motivational tools, and celebrating successes achieved through TEMPO. Each module focuses on different aspects of behavior change and self-management skills. The dyads complete worksheets as they move through the modules to apply the skills learned. Additionally, dyads have access to an extensive health library with information on a breadth of topics relevant to the challenges faced by men with prostate cancer and their caregivers.

Table 1. TIDieR guideline for reporting of interventions.

\begin{tabular}{cl}
\hline Items & \multicolumn{1}{c}{ Description } \\
\hline Brief Name & Tailored, wEb-based, psychosocial and physical activity self-Management PrOgram (TEMPO) \\
\hline Why & $\begin{array}{l}\text { TEMPO aims to increase dyads' confidence in using self-management strategies demonstrated to be } \\
\text { effective in addressing key psychosocial issues (e.g., dealing with stress) and assist dyads in developing } \\
\text { the self-regulatory skills necessary to meet the physical activity guidelines. }\end{array}$ \\
\hline
\end{tabular}

Dyads complete five modules: (a) identification of needs and priorities, (b) setting goals, (c) tracking progress and developing a coping plan, (d) strengthening support systems, and (e) maintaining behavior change beyond TEMPO. Modules focus on specific aspects of the behavior change process and integrate key persuasive technology techniques (e.g., primary task support). Each module specifies online

What (materials and (e.g., worksheets to set goals) and offline (e.g., practicing chosen skills) activities. In addition to modules, procedures) TEMPO includes a health library, incorporating 49 factsheets based on the most up-to-date evidence on self-management and physical activity. The health library includes eight sections: (a) communicating with your health care team, (b) treatment decision-making, (c) dealing with stress and worry, (d) supporting each other, (e) getting the support you need, (f) wanting to feel more fit and healthy, (g) getting on top of symptoms, and (h) caregiving. TEMPO is available in French and in English.

Who provided TEMPO is a self-directed intervention, whereby no external guidance is provided. All the support to navigate the intervention is included in its design.

Participants randomized to TEMPO are sent an email with a brief, illustrated instructional guide on creating a TEMPO account, and on accessing the modules. They are also invited to schedule a phone call How $\quad$ with a RA to review the registration instructions, receive support with account creation, and/or receive
assistance with module access as required. Once dyads use Module 1 to identify their needs, they can use the appropriate factsheets to get ideas for self-management strategies to address these and set their goals accordingly.

Where Each module becomes immediately available upon completion of the preceding module. If participants are not completing the modules at the expected pace ( 2 weeks per module), a maximum of two e-mail reminders are sent.

When and How much

As a self-directed intervention, TEMPO can be completed where participants prefer, as long as they have an internet connection.

Tailoring

Dyads complete a needs assessment in Module 1 and based on their answers, they can prioritize issues and set goals to work on throughout TEMPO.

Following our initial acceptability study: (a) new health library content was added to help participants

Modifications engage in physical activity during COVID-19-related confinement, (b) streamlining the content of the modules, and (c) instead of releasing modules every two weeks, having them available as soon as the previous one is completed. 
The development of TEMPO has been an iterative process with continuous input from men with prostate cancer, their caregivers, and experts from the field. The preliminary version of TEMPO was reviewed by a man diagnosed with prostate cancer and a caregiver for initial feedback. Following this review, content was streamlined, and the sailing metaphor used throughout was toned down. Then, we undertook an acceptability study early on in the development of the intervention, so that any changes could be made before more extensive testing. [37,38]. In the acceptability study [37], dyads endorsed TEMPO's self-directed and dyadic format. The dyads felt the program responded to their needs, and they reported learning new self-management skills, mainly physical activity (less psychosocial self-management strategies) as a way of responding to a range of physical and emotional concerns.

The next step in evaluating TEMPO is a pilot study whereby a priori criteria have been established (see Table 2) to determine TEMPO's feasibility and acceptability. The objectives of this pilot randomized controlled trial (RCT) were to (a) examine its feasibility, which includes rates of recruitment and refusal, questionnaire completion (including questionnaires for future cost-utility analysis), and protocol infringement; (b) examine the acceptability of TEMPO as evidenced by attrition, adherence, satisfaction, and perceived usefulness; and (c) estimate the clinical significance on anxiety and quality of life (primary outcomes, Supplementary Material S2), as well as depression, self-management skills, physical activity, self-efficacy, and appraisal (secondary outcomes) [39].

Table 2. A priori feasibility and acceptability benchmarks [39].

\begin{tabular}{|c|c|c|}
\hline Criteria & Benchmarks & Results \\
\hline \multicolumn{3}{|c|}{ Feasibility } \\
\hline Recruitment rate & 8 dyads/month across sites & 6.1 dyads (or patients)/month \\
\hline Refusal rate & $<45 \%$ & $34 \%$ \\
\hline Missing data & $<10 \%$ & $<10 \%$ \\
\hline Protocol infringement & Amenable to change & None \\
\hline \multicolumn{3}{|c|}{ Acceptability } \\
\hline Attrition & $<25 \%$ across groups & $19 \%$ \\
\hline Adherence & $75 \%$ of dyads adhere to modules & $45 \%$ \\
\hline System usability (satisfaction) & High system usability reported & Above average \\
\hline \multicolumn{3}{|c|}{ Clinical Significance } \\
\hline Effect size & 0.2 on the primary outcomes & $\begin{array}{c}\text { Anxiety }=0.24 \\
\text { Quality of life-mental }=0.38 \\
\text { Quality of life-physical }=0.30\end{array}$ \\
\hline $\begin{array}{l}\text { Minimal clinically important } \\
\text { difference improvement }\end{array}$ & $\begin{array}{l}25 \% \text { of participants improve on the } \\
\text { primary outcomes by at least the minimal } \\
\text { clinically important difference }\end{array}$ & $\begin{array}{c}\text { Anxiety }=\text { yes } \\
\text { Quality of life-mental = yes } \\
\text { Quality of life-physical = patient no, } \\
\text { caregiver yes }\end{array}$ \\
\hline
\end{tabular}

\section{Materials and Methods}

\subsection{Design}

Multi-center, stratified, 1:1 parallel, two-group, pilot RCT (NCT04304196), guided by the CONSORT [40] checklist and its adaptation for pilot trials [41].

\subsection{Participants}

A convenience sample of men with prostate cancer and their caregivers (as a dyad) were recruited between April 2020 and February 2021 from six sites in Montreal, Calgary, Toronto, and Vancouver (Canada). Towards the end of the pilot, men alone were also enrolled, as they expressed a dire need for the intervention (these men did have a caregiver with whom they could use TEMPO). Ethics approval was obtained from each site. Men with prostate cancer (local or metastasized) were eligible, if they received treatment (i.e., surgery, chemotherapy, radiation therapy, hormone therapy, and/or brachytherapy) within 
the past two years or were scheduled to receive treatment before the end of the study, and ideally identified a primary caregiver willing to participate. Caregivers were eligible, if they were identified by the man with prostate cancer as the primary source of support, had not been diagnosed with or treated for cancer in the past year, and agreed to participate in the study. Both members of the dyad needed to have access to the internet and understand English or French.

\subsection{Recruitment Procedures}

Participants were recruited by research assistants (RAs) at each site. At some sites, patients were referred to the RA by clinicians, or self-referred after seeing the study poster or pamphlet. At other sites, RAs called directly patients who had previously consented to be contacted about research. Social media were also used to recruit from local community organizations and support groups; interested individuals called local RAs for more information. If the patient was interested, the RA confirmed eligibility of both the patient and caregiver and those eligible completed the online consent form. Once participants consented, they received a link to complete the online baseline questionnaire.

\subsection{Randomization and Blinding}

Upon completion of the baseline questionnaire, the project coordinator randomized dyads (or solo patients), with an allocation ratio of 1:1 to TEMPO or usual care, using a computer-generated randomization schedule with random block sizes of 2 or 4, stratified on anxiety (Hospital Anxiety and Depression Scale-Anxiety subscale) [42]. Using an automated interface that was programmed by the study statistician, only the project coordinator was involved in stratification and randomization to ensure allocation concealment and avoid selection bias. The RAs did not have access to the randomization schedule. Participants were not blinded to group allocation, but were blinded to the study outcomes to reduce potential biases.

\subsection{TEMPO Intervention Group}

Participants randomized to TEMPO were emailed the website link (https:/ / tempo. truenth.ca/, accessed on 26 November 2021) with a brief, instructional guide for creating an account and navigating the website. Dyads could call an RA, if they needed assistance with account creation and/or navigating the website. See Table 1 for a complete description of TEMPO following TIDieR guideline [36].

\subsection{Wait-List Control Group}

Participants randomized to the control group were on a wait list, and given access to TEMPO upon return of their follow-up questionnaire.

All participants continued usual care as per the referring center resources and protocols.

\subsection{Data Collection}

Data collection included eligibility screening checklist at the time of recruitment (T0), a baseline questionnaire (T1), and 3-month follow-up questionnaire (T2). All questionnaires were available online on SimpleSurvey in French and English, to be completed by the patients and caregivers individually.

\subsubsection{Baseline Questionnaire (T1)}

Hospital Anxiety and Depression Scale (HADS) [42] includes 14 items equally divided across the Anxiety and Depression subscales. Subscale scores range from 0-21, with higher scores indicating higher symptoms of anxiety and depression. The Hospital Anxiety and Depression Scale has established reliability in English $(\alpha=0.68-0.93)$ [43] and in French $(\alpha=0.79-0.89)$ [44].

The 12-item Short Form Health Survey (SF-12) [45] measures quality of life, and includes a physical component score (PCS) and a mental component score (MSC). Scores 
are standardized from $0-100$, with higher scores indicating higher quality of life. Internal consistency of the physical component score $(\alpha=0.82)$ and mental component score $(\alpha=0.75)$ are adequate $[46,47]$. SF-12 will also be used in future cost-utility analyses of TEMPO.

Perceived Stress Scale (PSS) [48] (10 items) to report the frequency of feelings of stress. The total score was used, with higher scores indicating higher stress. This scale has adequate reliability and validity in English $(\alpha=0.74-0.91)$ [49] and French $(\alpha=0.73-0.81)$ [50].

Health Education Impact Questionnaire (heiQ v3.0) [51] consists of 40 items across eight subscales: (a) positive and active engagement in life, (b) skill acquisition, (c) constructive attitude, (d) self-monitoring, (e) health services navigation, (f) social integration, (g) health-directed activity, and (h) distress [51]. In line with TEMPO, patients responded to the first six subscales, and caregivers responded to the full questionnaire. Higher scores indicate higher levels on that subscale. Reliability is confirmed across subscales $(\alpha=\geq 0.70)$, in English [52] and French [51,53].

Health Literacy Questionnaire (HLQ) [54] has 44 items, but dyads completed the two most relevant subscales for TEMPO: (a) having sufficient information (4 items) and (b) actively managing my health (5 items). Higher scores indicate higher health literacy. This scale has adequate validity and reliability in both languages $(\alpha=0.76-0.94)[54,55]$.

International Physical Activity Questionnaire-Short Form (IPAQ-SF) [56], a 7-item measure of frequency and duration of vigorous-/moderate-intensity physical activity, walking, and sitting. Activities must be performed for at least 10 minutes. This scale has been found to be valid and reliable, with an overall Spearman's $\rho$ of 0.80 [56].

Physical Activity Plan and Intention [57], an 8-item questionnaire that measures participants' indicators of (a) planned physical activity and (b) intentions. On a 7-point Likert-type scale, participants indicated their agreement with the items and higher scores = higher planned physical activity and intention.

Multidimensional Self-Efficacy for Exercise Scale (MSES) [58] (9 items) to assess selfefficacy for exercise participation, including (a) task (e.g., follow directions to complete exercise), (b) coping (e.g., exercise when you lack energy), and (c) scheduling (e.g., include exercise in your daily routine). Higher scores indicate greater self-efficacy. This scale has excellent reliability ( $\alpha=0.83-0.91)$ and validity [58].

Dyadic Coping Inventory (DCI) [59] (37 items, $\alpha=0.63-0.84$ ) [60] to capture how partners support one another in response to individual and collective stressors [61]. This scale has shown to be reliable and valid for use across 25 languages [61]. The total score was used, with higher scores indicating higher levels of dyadic coping.

Revised Dyadic Adjustment Scale (RDAS) [62], a 14-item questionnaire assessing dyadic consensus, satisfaction, cohesion, and affective expression. Higher scores indicate higher dyadic adjustment. Cronbach's alpha ranged from 0.89 to 0.95 [63]. The measure was optional.

Use of Healthcare services and change in employment (9 items) questionnaire [64] to assess (a) consultation with health care professionals, (b) hospital admissions, (c) medications purchased, (d) use of community services, (e) medical care costs, (f) change in employment, $(\mathrm{g})$ change in hours worked, and $(\mathrm{h})$ performance at work. This questionnaire was included mainly to assess its feasibility for future cost-utility analyses in a larger trial.

Demographics and care information. All participants answered demographic questions, and questions about the cancer diagnosis and its treatment.

\subsubsection{Follow-Up (T2) Questionnaires}

The follow-up questionnaires included all the measures from T1, as well as a communitybased resources survey to assess usual care and co-interventions, and the System Usability Scale [65] (10 items) to assess participants' view of TEMPO's usability. The average score on the System Usability Scale is calculated where scores above 68 are considered above average. To complement the System Usability Scale, the T2 questionnaire also included a 32-item TEMPO feedback survey (based on the concepts of the Technology 
Acceptance Model [66-68]) to identify the strengths and weaknesses of the program (higher scores $=$ positive feedback, see Supplementary Materials S1).

\subsubsection{Dyadic Exit Interviews}

If at a minimum one member of the dyad returned their T2 questionnaire, the dyad was invited to a semi-structured, telephone or online, exit interview. The purpose of the interview was to further explore TEMPO's perceived usefulness. An interview guide was developed, but questions were tailored to the participants' TEMPO feedback survey answers. The interviews were conducted by the same experienced RA who did them in the initial acceptability study [37].

\subsubsection{Study Logs}

Study logs were kept by local RAs and the project coordinator to collect data on: (a) number of individuals approached, (b) number of individuals self-referred, (c) number of eligible and ineligible individuals, (d) number of individuals who decline to participate (with reason), (e) number of participants consented and randomized, (f) number of participants who withdrew (with reason), and (g) number of participants who dropped out (with reason).

\subsubsection{User Tracking Information}

Adherence was measured from user tracking information from the TEMPO website, including: number of logins, time spent on each module, number of times logged into each module, modules completed, and worksheets completed within the modules.

\subsection{Data Analysis}

The quantitative data analysis was completed using SAS University Edition [69], STATA 15 [70], and R version 3.1.2 [71].

\subsubsection{Feasibility and Acceptability Data}

The a priori benchmarks for feasibility and acceptability are detailed in Table 2. Feasibility and acceptability data included recruitment, refusal, attrition, missing data, and adherence rates as well as usability. As part of missing data, the feasibility of collecting data on resource utilization and costs was particularly examined in preparation of a future larger trial. Any protocol infringement and changes made were also noted. Adherence was calculated based on the number of modules completed by each dyad, where a completed module meant that each page was viewed, and it took more than 15 min to complete. Adherence was categorized as high (all 5 modules completed), moderate (3-4 modules completed), and non-adherent (1-2 modules completed). Usability of TEMPO was assessed by calculating the average score on the System Usability Scale [65].

\subsubsection{Clinical Significance}

Baseline characteristics were described for the men with prostate cancer and the caregivers by study group. For each outcome, the effect size was computed as the study group mean difference, divided by the pooled standard deviation [72]. An effect size of at least 0.2 was considered a clinically significant change, given this is a pilot. Moreover, for each outcome, complete data analysis (including dyads and single patients), was performed using the Generalized Estimating Equations approach (GEE) [73]. This approach accounts for the correlation of the dyad outcome and the effect size was computed as the 'Beta' estimate of the intervention group in the linear regression model divided by the pooled standard deviation obtained from the unadjusted analysis [74,75]. Additional analyses were performed for the primary outcomes with complete dyad at three months. Additionally, the minimal clinically important difference was calculated for the primary outcomes, striving for $25 \%$ of participants improving by the minimal clinically important difference. The minimal clinically important difference is not available for HADS and SF-12 among cancer 
patients and caregivers, but we relied on validated minimal clinically important difference from other populations: MCID HADS = 1.5 [76], SF-12 PCS = 3.3, and SF-12 MCS = 3.8 [77]

\subsubsection{Analysis of Exit Interviews}

Interview transcripts were coded by an RA using the NVivo 12 software [78]. Codes were words or statements pertaining to TEMPO's acceptability. To enhance credibility, codes were discussed at regular team meetings. Codes were compared across transcripts to identify key themes.

\section{Results}

\subsection{Study Participants}

Figure 1 details participants' flow through the study. A total of 33 patient-caregiver dyads and 16 men with prostate cancer were randomized. Table 3 provides a description of the sociodemographic characteristics. Three-quarters of caregivers and men were 61 years old or older and retired. The caregivers were mostly men's spouses and living with the patient. Two thirds of men were diagnosed with early-stage prostate cancer, and most were at least one year from the diagnosis. The most common co-morbidities for the men and their caregivers were hypertension (29.4-52.6\%) and arthritis (18.8-36.8\%). Qualitative interviews were conducted, with 12 dyads (in two dyads patients and caregivers were interviewed separately) and one patient who participated without a caregiver.

Table 3. Patient and caregiver demographics.

\begin{tabular}{|c|c|c|c|c|}
\hline \multirow{3}{*}{ Characteristics } & \multicolumn{2}{|c|}{ Men with Prostate Cancer } & \multicolumn{2}{|c|}{ Caregivers } \\
\hline & $\begin{array}{c}\text { TEMPO } \\
(n=26)\end{array}$ & $\begin{array}{l}\text { Control } \\
(n=23)\end{array}$ & $\begin{array}{c}\text { TEMPO } \\
(n=16)\end{array}$ & $\begin{array}{l}\text { Control } \\
(n=17)\end{array}$ \\
\hline & $n(\%)$ & $n(\%)$ & $n(\%)$ & $n(\%)$ \\
\hline \multicolumn{5}{|l|}{ Age } \\
\hline$\leq 60$ & $6(23.1)$ & $6(26.1)$ & $4(25.0)$ & $6(35.3)$ \\
\hline$\geq 61$ & $20(76.9)$ & $17(73.9)$ & $12(75.0)$ & $11(64.7)$ \\
\hline \multicolumn{5}{|l|}{ Sex } \\
\hline Male & $26(100)$ & $26(100)$ & $1(6.2)$ & $1(6.2)$ \\
\hline Female & & & $15(93.8)$ & $15(93.8)$ \\
\hline \multicolumn{5}{|l|}{ Language } \\
\hline English & $23(88.5)$ & 21(91.3) & $15(93.7)$ & $15(88.2)$ \\
\hline French & 0 & $1(4.3)$ & 0 & 0 \\
\hline Other & $3(11.5)$ & $1(4.3)$ & $1(6.3)$ & $2(11.8)$ \\
\hline \multicolumn{5}{|l|}{ Country of Birth } \\
\hline Canada & $20(76.9)$ & $17(73.9)$ & $13(81.3)$ & $12(70.6)$ \\
\hline Other & $6(23.1)$ & $6(26.1)$ & $3(18.7)$ & $5(29.4)$ \\
\hline \multicolumn{5}{|l|}{ Education } \\
\hline High school or below & 0 & $2(8.7)$ & $1(6.3)$ & $4(23.5)$ \\
\hline Post-secondary diploma & $10(38.5)$ & $10(43.5)$ & $4(25.0)$ & $3(17.6)$ \\
\hline Undergraduate university & $6(23.0)$ & $5(21.7)$ & $6(37.5)$ & $5(29.4)$ \\
\hline Graduate diploma & $10(38.5)$ & $6(26.1)$ & $5(31.2)$ & $5(29.4)$ \\
\hline \multicolumn{5}{|l|}{ Employment } \\
\hline Full time & $5(19.2)$ & $7(30.4)$ & $1(12.5)$ & $2(16.7)$ \\
\hline Part time & $2(7.7)$ & $1(4.3)$ & $5(62.5)$ & $2(16.7)$ \\
\hline Retired & $15(57.7)$ & $14(60.9)$ & $2(25.0)$ & $7(58.3)$ \\
\hline Other & $4(15.4)$ & $1(4.3)$ & $0(0.0)$ & $1(8.3)$ \\
\hline (Missing) & & & (8) & (5) \\
\hline \multicolumn{5}{|l|}{ Patient-Caregiver Relationship } \\
\hline Spouse/Partner & $23(88.5)$ & $20(87.0)$ & $16(100)$ & $16(94.1)$ \\
\hline Other (friend, relative, etc.) & $3(11.5)$ & $3(13.0)$ & 0 & $1(5.9)$ \\
\hline
\end{tabular}


Table 3. Cont.

\begin{tabular}{|c|c|c|c|c|}
\hline \multirow{3}{*}{ Characteristics } & \multicolumn{2}{|c|}{ Men with Prostate Cancer } & \multicolumn{2}{|c|}{ Caregivers } \\
\hline & $\begin{array}{l}\text { TEMPO } \\
(n=26)\end{array}$ & $\begin{array}{l}\text { Control } \\
(n=23)\end{array}$ & $\begin{array}{c}\text { TEMPO } \\
(n=16)\end{array}$ & $\begin{array}{l}\text { Control } \\
(n=17)\end{array}$ \\
\hline & $n(\%)$ & $n(\%)$ & $n(\%)$ & $n(\%)$ \\
\hline Living Together & $22(84.6)$ & $20(87.0)$ & $15(93.8)$ & $16(94.1)$ \\
\hline \multicolumn{5}{|l|}{ Marital Status } \\
\hline Married/common law & $22(84.6)$ & $22(95.7)$ & $15(93.8)$ & $17(100.0)$ \\
\hline Other & $4(15.4)$ & $1(4.3)$ & $1(6.2)$ & 0 \\
\hline \multicolumn{5}{|l|}{ Time Since Diagnosis } \\
\hline$<6$ months & $1(3.8)$ & $1(4.3)$ & & \\
\hline $6-12$ months & $5(19.2)$ & $2(8.7)$ & & \\
\hline $12-24$ months & $16(61.5)$ & $10(43.5)$ & & \\
\hline$>24$ months & $4(15.4)$ & $10(43.5)$ & & \\
\hline \multicolumn{5}{|l|}{ Stages } \\
\hline Early & $16(61.5)$ & $14(60.9)$ & & \\
\hline Advanced & $8(30.8)$ & $9(39.1)$ & & \\
\hline Don't know & $2(7.7)$ & $0(0.0)$ & & \\
\hline \multicolumn{5}{|c|}{ Treatment (can have more than one) } \\
\hline Surgery & $17(65.4)$ & $16(69.6)$ & & \\
\hline Chemo & $2(7.7)$ & $1(4.3)$ & & \\
\hline Radio & $13(50.0)$ & $5(21.7)$ & & \\
\hline Hormonal & $13(50.0)$ & $9(39.1)$ & & \\
\hline Brachytherapy & $5(19.2)$ & $3(13.0)$ & & \\
\hline Other & $5(19.2)$ & $3(13.0)$ & & \\
\hline
\end{tabular}

\subsection{Feasibility}

All feasibility benchmarks were achieved (see Table 2), with the exception of recruitment, with 6.1 dyads (or patients)/month recruited (instead of the benchmark of 8 dyads/month). No major protocol infringements occurred.

Feasibility of Cost-Utility Data Collection Methods

The Use of Healthcare Services Questionnaire was found to be feasible and acceptable by participants, suggesting that collecting self-reported resource use and cost data for a subsequent cost-utility analysis will be possible. Participants in the control group reported the following use of health care services-Physician consults: at baseline $=2.50(\mathrm{SD}=2.42)$ and at follow-up $3.61(\mathrm{SD}=3.18)$ and allied health consults: at baseline $=2.66(\mathrm{SD}=2.70)$ and at follow-up $5.94(\mathrm{SD}=6.66)$. Participants in the TEMPO group reported-Physician consults: at baseline of $1.77(\mathrm{SD}=1.73)$ and at follow-up $2.77(\mathrm{SD}=3.47)$ and allied health consults: at baseline $2.61(\mathrm{SD}=3.09)$ and at follow-up $2.71(\mathrm{SD}=3.89)$.

\subsection{Acceptability}

The attrition rate across groups was 19\%, below our $25 \%$ benchmark. The patients reported a System Usability Scale score of $75(\mathrm{SD}=15.9)$, and the caregivers reported a higher score of $81.8(\mathrm{SD}=15.0)$. This means that overall, both patients and caregivers reported above average system usability with TEMPO. Participants interviewed added that $T E M P O$ is user-friendly, straightforward to navigate, and logical in terms of the sequence of modules. One participant explained:

I liked that the sessions were set up in such a way that it was thought-provoking and engaging. I think sometimes when you go through these-like I've done 360 processes in business and things like that and you know, your brain starts to drift, but I felt quite engaged throughout the entire session. I thought it was very relevant (man, 11072-12072) 
Suggestions for improvement included: incorporating more options to complete action plans online and enhancing the functionality of certain features for a mobile device.

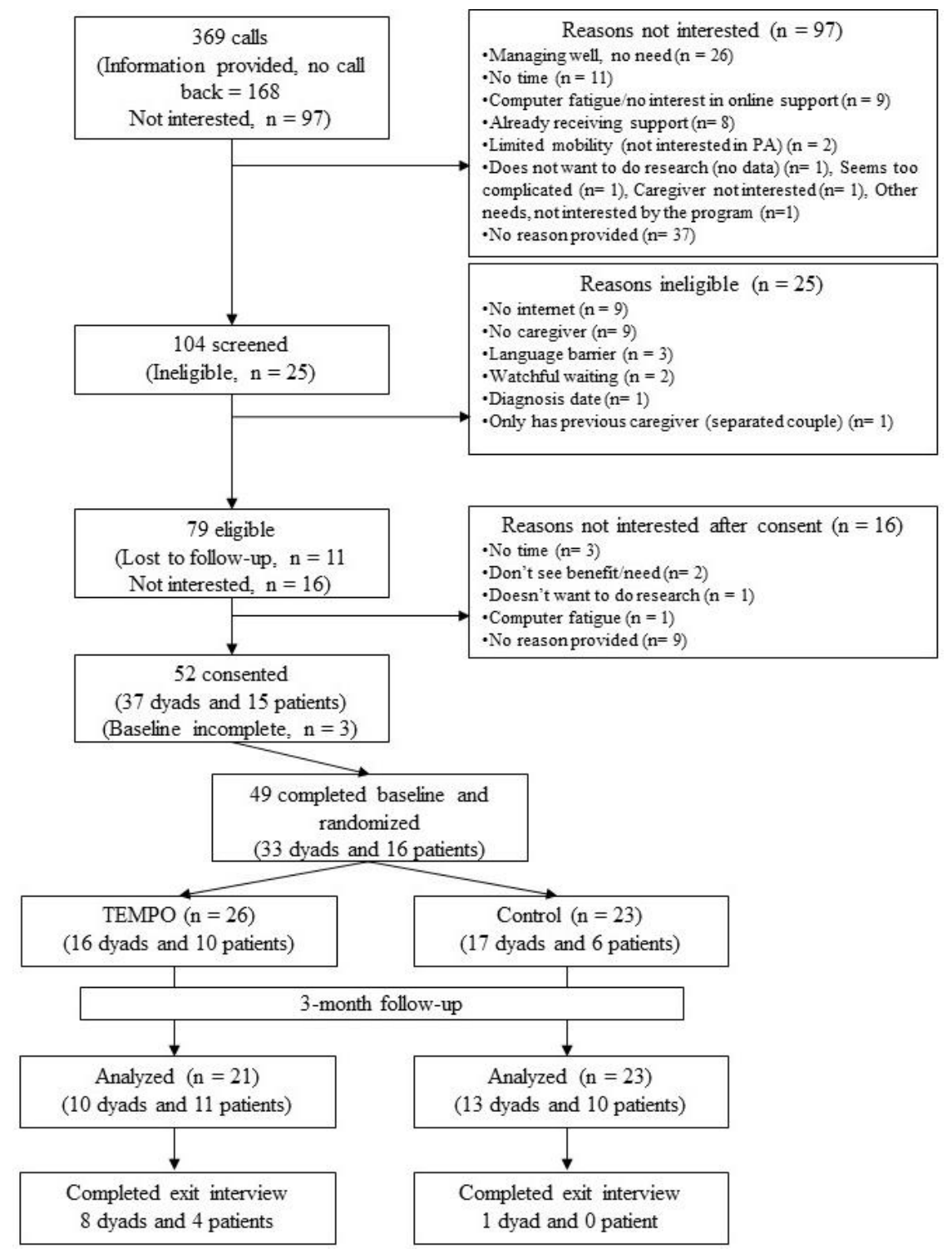

Figure 1. Flow diagram of recruitment and enrollment in TEMPO.

\subsubsection{TEMPO Feedback Survey}

Items that scored the lowest on the TEMPO feedback survey were (see Supplementary Material S1): The information presented in the health library was new to me, TEMPO was applicable to my situation, and TEMPO was tailored. During the interviews participants explained that the main reason for the information not being new was that they joined TEMPO too late after their diagnosis and they found the information they needed before having access to TEMPO. Most participants did not receive the needed information from their health care professionals, rather they undertook independent information-seeking (e.g., internet, library, support groups). This independent learning created doubt about the credibility of the information found, and whether what they were doing was "correct". For these participants, TEMPO gave them "peace of mind" (man, 1338-1335): "(TEMPO) reinforced that our approach and attitude were correct and that it had good resources to get further information" (man, 1338-1335). Through using TEMPO, a few participants identified some issues that they realized needed to be addressed (e.g., dyadic relationship). 
In terms of tailoring, interviewed participants explained that, despite the needs assessment in Module 1 to tailor TEMPO content, TEMPO was not adapted to their prognosis, time since diagnosis (e.g., library content on treatment decision-making should be hidden if in survivorship phase), fitness level, and the type of support system they had (e.g., Module 4 was not relevant for those with a good support system). One participant explained:

Different people get on TEMPO at different stages ( . . ) and different people fork in different ways. (...) A person could argue you need 10 different TEMPOs and that just wouldn't be realistic. But the major branches for me would be first step diagnosis but the person has not yet made a decision about treatment. (... ) And then once you've made a decision about treatment ( . . ) these are all major branches where people stop having things in common (man, 81006-82006)

For caregivers, in particular, learning new skills and using these on a day-to-day basis were items that scored low on the TEMPO feedback survey. During the exit interviews, it was clarified that the most frequent skills learned were being more active as a couple and communicating more with each other (especially because of the needs assessment in Module 1). One caregiver said: We did it together, we would sit down and do the quiz together. I found a couple of things about it by going through it, and realized: "Oh, he hasn't talked about this, maybe we should talk." ( . . . ) It was beneficial for communication (caregiver, 32058).

Beyond learning specific self-management skills, what participants found useful were the behavior change modules (more than the factsheets). This is because the modules gave participants a generalizable, clear process or guidelines on addressing needs (often using knowledge they already had) and how to go about integrating PA and other selfmanagement skills. One participant said: I was engaged by all of the modules. I would say that was the best part of it (TEMPO)_because we worked on it together-was the differences in our responses. So, I think, versus any specific module I think it was more (... ), the process (man, 11072-12072). Another caregiver said: TEMPO provides some useful guidelines as to how to go about this (working out), and some useful suggestions about different exercise regimens and things to do (caregiver, 11057-12057).

The TEMPO feedback items that scored the highest were (see Supplementary Material S1): I trust the information delivered through TEMPO, working through TEMPO as a pair made the process more enjoyable (especially for caregivers), and TEMPO should be integrated in routine care (especially for the men with prostate cancer). Interviewed participants explained TEMPO was the only resource they came across that explicitly involved the caregiver. The greatest value of that was accountability towards the other person of the dyad to achieve goals, and doing things together (e.g., more communication as couples walked together). The different worksheets helped each member of the dyad obtain more insights into how the other was feeling:

Going through that section (mood-monitoring tool) about how you're feeling (...) certainly gave me some insight into how (patient) was experiencing things. I think we have a very good relationship and we assume we're on the same wavelength, but that's not always the case (caregiver, 11057-12057)

In a few dyads one partner took the lead and only brought the other member in at critical milestones (e.g., deciding on the action plan) and when they wanted to share relevant information (e.g., one member of the dyad would go through the Health Library and only bring what was relevant to the other member). In other dyads, both partners completed some or all modules sitting in front of a computer together. Most dyads revisited TEMPO modules after their initial completion.

\subsubsection{Adherence}

Three men who were participating alone and two dyads never registered to TEMPO $(19 \%)$. For one dyad, the user tracking did not work. In terms of those who logged in $(n=20), 70 \%(n=14)$ logged in at least 3 times (mean 5.9 times, SD $=4.9)$. The modules 
most often accessed and used for the longest amount time were Module 1 (average log ins 2.8, $\mathrm{SD}=2.3$; time spent mean $=25.9 \mathrm{~min}, \mathrm{SD}=24.0 \mathrm{~min}$ ) and Module 2 (average log ins 2.6, $\mathrm{SD}=3.2$; time spent mean $=42.3 \mathrm{~min}, \mathrm{SD}=72.1 \mathrm{~min}$ ). On average, participants spent $104 \mathrm{~min}(\mathrm{SD}=129 \mathrm{~min})$ on TEMPO. Modules most often completed as defined by $100 \%$ pages viewed and spending at least $15 \mathrm{~min}$ were also Modules $1(60 \%, n=12)$ and $2(40 \%, n=8)$. Other modules were completed by $10-15 \%$ of participants. Using the same criteria for module completion, 1.4/5 modules on average were completed and $45 \%$ $(n=9)$ of participants were categorized as adhering to the modules. The worksheet most often completed was the Module 1 -unmet needs assessment $(n=17,85 \%)$, followed by the Module 2-goal setting worksheet $(n=12,60 \%)$. The remaining worksheets were completed by $38 \%$ of participants $(n=10)$.

\subsection{Primary Outcomes}

Benchmarks for clinical significance were mostly met. Table 4 presents effects' sizes for men and caregivers separately and combined. Participants reported clinically significant improvements in anxiety (effect size $=0.24$ ). Anxiety decreased by the minimal clinically important difference in $42.9 \%$ of patients and $44.4 \%$ of caregivers using TEMPO, exceeding rates in the control group $(39.1 \%$ patients and $30.8 \%$ caregivers, Odds Ratio $=1.48)$.

Table 4. Baseline and post-test scores for primary and secondary outcomes for patients and caregivers.

\begin{tabular}{|c|c|c|c|c|c|c|c|c|c|c|c|}
\hline \multirow{4}{*}{ Outcomes } & \multicolumn{5}{|c|}{ Men with Prostate Cancer } & \multicolumn{5}{|c|}{ Caregivers } & \multirow{4}{*}{$\begin{array}{l}\text { Combined } \\
\text { Effect Size * }\end{array}$} \\
\hline & \multicolumn{2}{|c|}{ Baseline } & \multicolumn{2}{|c|}{ Follow-Up } & \multirow{3}{*}{$\begin{array}{l}\text { Effect } \\
\text { Size }\end{array}$} & \multicolumn{2}{|c|}{ Baseline } & \multicolumn{2}{|c|}{ Follow-Up } & \multirow{3}{*}{$\begin{array}{l}\text { Effect } \\
\text { Size }\end{array}$} & \\
\hline & $\begin{array}{l}\text { TEMPO } \\
(n=26)\end{array}$ & $\begin{array}{l}\text { Control } \\
(n=23)\end{array}$ & $\begin{array}{l}\text { TEMPO } \\
(n=21)\end{array}$ & $\begin{array}{l}\text { Control } \\
(n=23)\end{array}$ & & $\begin{array}{l}\text { TEMPO } \\
(n=16)\end{array}$ & $\begin{array}{l}\text { Control } \\
(n=17)\end{array}$ & $\begin{array}{l}\text { TEMPO } \\
(n=10)\end{array}$ & $\begin{array}{l}\text { Control } \\
(n=13)\end{array}$ & & \\
\hline & $\begin{array}{l}\text { Mean } \\
\text { (SD) }\end{array}$ & $\begin{array}{l}\text { Mean } \\
\text { (SD) }\end{array}$ & $\begin{array}{l}\text { Mean } \\
\text { (SD) }\end{array}$ & $\begin{array}{l}\text { Mean } \\
\text { (SD) }\end{array}$ & & $\begin{array}{l}\text { Mean } \\
\text { (SD) }\end{array}$ & $\begin{array}{l}\text { Mean } \\
\text { (SD) }\end{array}$ & $\begin{array}{l}\text { Mean } \\
\text { (SD) }\end{array}$ & $\begin{array}{l}\text { Mean } \\
\text { (SD) }\end{array}$ & & \\
\hline \multicolumn{12}{|c|}{ Primary Outcomes } \\
\hline $\begin{array}{c}\text { Quality of Life } \\
\text { Mental } \\
\text { Physical } \\
\text { (missing) }\end{array}$ & $\begin{array}{l}48.0(8.5) \\
50.2(9.3) \\
\quad(0)\end{array}$ & $\begin{array}{l}46.1(9.2) \\
49.3(12.2) \\
\quad(0)\end{array}$ & $\begin{array}{l}49.3(10.3) \\
52.6(6.1) \\
(0)\end{array}$ & $\begin{array}{l}46.8(10.8) \\
49.1(12.5) \\
\quad(0)\end{array}$ & $\begin{array}{l}0.23 \\
0.35\end{array}$ & $\begin{array}{l}52.5(7.1) \\
52.7(8.0) \\
\quad(0)\end{array}$ & $\begin{array}{c}50.4(9.3) \\
51.6(7.9) \\
(1)\end{array}$ & $\begin{array}{c}54.7(5.3) \\
51.1(9.9) \\
(1)\end{array}$ & $\begin{array}{c}47.6(9.6) \\
49.2(8.6) \\
(0)\end{array}$ & $\begin{array}{l}0.87 \\
0.21\end{array}$ & $\begin{array}{l}0.38 \\
0.30\end{array}$ \\
\hline $\begin{array}{l}\text { Anxiety } \\
\text { (missing) }\end{array}$ & $\begin{array}{l}5.5(3.4) \\
(0)\end{array}$ & $\begin{array}{l}6.3(4.1) \\
(0)\end{array}$ & $\begin{array}{l}4.5(4.2) \\
(0)\end{array}$ & $\begin{array}{l}5.3(4.7) \\
(0)\end{array}$ & 0.19 & $\begin{array}{l}5.0(4.1) \\
(0)\end{array}$ & $\begin{array}{l}4.6(3.6) \\
(0)\end{array}$ & $\begin{array}{l}3.4(2.8) \\
(1)\end{array}$ & $\begin{array}{l}4.8(3.3) \\
(0)\end{array}$ & 0.43 & 0.24 \\
\hline \multicolumn{12}{|c|}{ Secondary Outcomes } \\
\hline $\begin{array}{l}\text { Depression } \\
\text { (missing) }\end{array}$ & $\begin{array}{c}3.6(3.4) \\
(0)\end{array}$ & $\begin{array}{l}5.0(4.2) \\
(0)\end{array}$ & $\begin{array}{l}3.7(4.4) \\
(0)\end{array}$ & $\begin{array}{l}4.8(4.3) \\
(0)\end{array}$ & 0.26 & $\begin{array}{c}2.3(2.5) \\
(0)\end{array}$ & $\begin{array}{c}3.1(2.2) \\
(0)\end{array}$ & $\begin{array}{c}1.2(1.6) \\
(1)\end{array}$ & $\begin{array}{c}3.4(3.0) \\
(0)\end{array}$ & 0.88 & 0.31 \\
\hline $\begin{array}{c}\text { Stress } \\
\text { (missing) }\end{array}$ & $\begin{array}{c}13.3(6.2) \\
(1)\end{array}$ & $\begin{array}{l}13.4(6.7) \\
(1)\end{array}$ & $\begin{array}{c}12.8(7.1) \\
(1)\end{array}$ & $\begin{array}{l}12.4(8.1) \\
(1)\end{array}$ & 0.05 & $\begin{array}{c}12.3(7.7) \\
(1)\end{array}$ & $\begin{array}{c}14.7(6.0) \\
(2)\end{array}$ & $\begin{array}{c}11.0(5.5) \\
(1)\end{array}$ & $\begin{array}{c}12.1(5.3) \\
(1)\end{array}$ & 0.35 & 0.04 \\
\hline $\begin{array}{l}\text { Self-Management } \\
\text { Positive engagement } \\
\text { Skill acquisition } \\
\text { Constructive attitudes } \\
\text { Self-monitoring }\end{array}$ & $\begin{array}{l}3.3(0.5) \\
3.0(0.4) \\
3.4(0.5) \\
3.3(0.3)\end{array}$ & $\begin{array}{l}3.1(0.6) \\
3.1(0.4) \\
3.3(0.7) \\
3.2(0.4)\end{array}$ & $\begin{array}{l}3.4(0.6) \\
3.3(0.4) \\
3.4(0.6) \\
3.4(0.4)\end{array}$ & $\begin{array}{l}3.2(0.6) \\
3.1(0.5) \\
3.3(0.7) \\
3.3(0.4)\end{array}$ & $\begin{array}{l}0.33 \\
0.44 \\
0.15 \\
0.25\end{array}$ & $\begin{array}{l}3.4(0.4) \\
3.1(0.5) \\
3.3(0.4) \\
3.3(0.4)\end{array}$ & $\begin{array}{l}3.1(0.4) \\
2.5(0.4) \\
3.0(0.4) \\
2.9(0.5)\end{array}$ & $\begin{array}{l}3.4(0.5) \\
2.9(0.4) \\
3.3(0.4) \\
3.2(0.4)\end{array}$ & $\begin{array}{c}3.1(0.4) \\
2.6(0.4) \\
3.3(0.4) \\
3(0.5)\end{array}$ & $\begin{array}{l}0.90 \\
0.75 \\
0.00 \\
0.43\end{array}$ & $\begin{array}{l}0.46 \\
0.48 \\
0.14 \\
0.29\end{array}$ \\
\hline $\begin{array}{c}\text { Health services } \\
\text { navigation }\end{array}$ & $3.3(0.4)$ & $3.4(0.5)$ & $3.3(0.5)$ & $3.4(0.6)$ & -0.18 & $3.2(0.4)$ & $2.7(0.4)$ & $3.1(0.1)$ & $2.6(0.7)$ & 0.92 & 0.26 \\
\hline $\begin{array}{l}\text { Social integration } \\
\text { and support } \\
\text { (missing) }\end{array}$ & $\begin{array}{c}3.1(0.5) \\
(0)\end{array}$ & $\begin{array}{c}3.1(0.6) \\
(0)\end{array}$ & $\begin{array}{c}3.2(0.6) \\
(1)\end{array}$ & $\begin{array}{c}3.1(0.6) \\
(1)\end{array}$ & 0.17 & $\begin{array}{c}3.1(0.5) \\
(2)\end{array}$ & $\begin{array}{c}2.7(0.6) \\
(7)\end{array}$ & $\begin{array}{c}3.1(0.8) \\
\quad(1)\end{array}$ & $\begin{array}{c}2.6(0.6) \\
(0)\end{array}$ & 0.73 & 0.34 \\
\hline $\begin{array}{l}\text { Health Literacy } \\
\text { Sufficient information } \\
\text { Actively managing } \\
\text { (missing) }\end{array}$ & $\begin{array}{c}3.0(0.5) \\
3.1(0.6) \\
\quad(1)\end{array}$ & $\begin{array}{c}3.0(0.6) \\
3.1(0.4) \\
\quad(1)\end{array}$ & $\begin{array}{l}3.1(0.5) \\
3.2(0.5) \\
\quad(1)\end{array}$ & $\begin{array}{l}3.1(0.6) \\
3.1(0.5) \\
\quad(1)\end{array}$ & $\begin{array}{l}0.00 \\
0.20\end{array}$ & $\begin{array}{c}3.2(0.5) \\
3.2(0.5) \\
\quad(1)\end{array}$ & $\begin{array}{c}3.2(0.5) \\
3.1(0.6) \\
(1)\end{array}$ & $\begin{array}{c}3.4(0.5) \\
3.4(0.6) \\
(1)\end{array}$ & $\begin{array}{c}3.1(0.7) \\
3.0(0.7) \\
(1)\end{array}$ & $\begin{array}{l}0.48 \\
0.61\end{array}$ & $\begin{array}{l}0.04 \\
0.38\end{array}$ \\
\hline $\begin{array}{l}\text { Physical Activity } \\
\text { (MET) }\end{array}$ & $\begin{array}{l}1894 \\
(1919)\end{array}$ & $\begin{array}{c}2365 \\
(3313)\end{array}$ & $\begin{array}{c}2521 \\
(1471)\end{array}$ & $\begin{array}{c}2253 \\
(1969)\end{array}$ & 0.17 & $\begin{array}{l}1953 \\
(2210)\end{array}$ & $\begin{array}{l}1410 \\
(1082)\end{array}$ & $\begin{array}{c}2020 \\
(1812)\end{array}$ & $\begin{array}{l}1713 \\
(1870)\end{array}$ & 0.17 & 0.15 \\
\hline $\begin{array}{l}\text { Physical Activity Plan } \\
\text { (missing) }\end{array}$ & $\begin{array}{l}4.2(2.1) \\
(1)\end{array}$ & $\begin{array}{c}3.7(2.2) \\
(2)\end{array}$ & $\begin{array}{c}4.7(2.0) \\
(1)\end{array}$ & $\begin{array}{c}3.5(1.8) \\
\text { (1) }\end{array}$ & 0.63 & $\begin{array}{c}4.8(2.0) \\
(1)\end{array}$ & $\begin{array}{c}4.3(1.9) \\
\text { (2) }\end{array}$ & $\begin{array}{c}5.0(1.4) \\
(1)\end{array}$ & $\begin{array}{l}4.6(1.9) \\
\text { (2) }\end{array}$ & 0.24 & 0.48 \\
\hline $\begin{array}{l}\text { Physical Activity } \\
\text { Intention } \\
\text { (missing) }\end{array}$ & $\begin{array}{c}4.6(2.0) \\
(3)\end{array}$ & $\begin{array}{c}3.9(2.1) \\
(3)\end{array}$ & $\begin{array}{c}4.8(1.7) \\
(1)\end{array}$ & $\begin{array}{c}4.1(1.5) \\
(1)\end{array}$ & 0.44 & $\begin{array}{c}5.2(1.8) \\
(3)\end{array}$ & $\begin{array}{c}4.8(1.9) \\
(4)\end{array}$ & $\begin{array}{c}4.9(1.2) \\
(3)\end{array}$ & $\begin{array}{c}4.4(1.5) \\
(4)\end{array}$ & 0.36 & 0.38 \\
\hline
\end{tabular}


Table 4. Cont.

\begin{tabular}{|c|c|c|c|c|c|c|c|c|c|c|c|}
\hline \multirow{4}{*}{ Outcomes } & \multicolumn{5}{|c|}{ Men with Prostate Cancer } & \multicolumn{5}{|c|}{ Caregivers } & \multirow{4}{*}{$\begin{array}{l}\text { Combined } \\
\text { Effect Size }\end{array}$} \\
\hline & \multicolumn{2}{|c|}{ Baseline } & \multicolumn{2}{|c|}{ Follow-Up } & \multirow{3}{*}{$\begin{array}{l}\text { Effect } \\
\text { Size }\end{array}$} & \multicolumn{2}{|c|}{ Baseline } & \multicolumn{2}{|c|}{ Follow-Up } & \multirow{3}{*}{$\begin{array}{l}\text { Effect } \\
\text { Size }\end{array}$} & \\
\hline & $\begin{array}{c}\text { TEMPO } \\
(n=26)\end{array}$ & $\begin{array}{l}\text { Control } \\
(n=23)\end{array}$ & $\begin{array}{c}\text { TEMPO } \\
(n=21)\end{array}$ & $\begin{array}{l}\text { Control } \\
(n=23)\end{array}$ & & $\begin{array}{c}\text { TEMPO } \\
(n=16)\end{array}$ & $\begin{array}{l}\text { Control } \\
(n=17)\end{array}$ & $\begin{array}{c}\text { TEMPO } \\
(n=10)\end{array}$ & $\begin{array}{l}\text { Control } \\
(n=13)\end{array}$ & & \\
\hline & $\begin{array}{l}\text { Mean } \\
\text { (SD) }\end{array}$ & $\begin{array}{l}\text { Mean } \\
\text { (SD) }\end{array}$ & $\begin{array}{l}\text { Mean } \\
\text { (SD) }\end{array}$ & $\begin{array}{l}\text { Mean } \\
\text { (SD) }\end{array}$ & & $\begin{array}{l}\text { Mean } \\
\text { (SD) }\end{array}$ & $\begin{array}{l}\text { Mean } \\
\text { (SD) }\end{array}$ & $\begin{array}{l}\text { Mean } \\
\text { (SD) }\end{array}$ & $\begin{array}{l}\text { Mean } \\
\text { (SD) }\end{array}$ & & \\
\hline $\begin{array}{l}\text { Physical Activity } \\
\text { Self-Efficacy } \\
\text { (missing) }\end{array}$ & $\begin{array}{c}73.0 \\
(21.5) \\
(4)\end{array}$ & $\begin{array}{c}66.2 \\
(20.4) \\
(2)\end{array}$ & $\begin{array}{c}78.5(16.5) \\
(1)\end{array}$ & $\begin{array}{c}61.6(26.2) \\
(1)\end{array}$ & 0.76 & $\begin{array}{c}75.7 \\
(20.1) \\
(1)\end{array}$ & $\begin{array}{c}70.9 \\
(16.6) \\
(2)\end{array}$ & $\begin{array}{c}81.2 \\
(13.9) \\
(1)\end{array}$ & $\begin{array}{c}68.1 \\
(21.3) \\
(1)\end{array}$ & 0.71 & 0.72 \\
\hline $\begin{array}{l}\text { Dyadic Coping } \\
\text { (missing) }\end{array}$ & $\begin{array}{c}124.9 \\
(24.7) \\
(4)\end{array}$ & $\begin{array}{c}128.0 \\
(19.5) \\
(2)\end{array}$ & $\begin{array}{c}132.8 \\
(14.8) \\
(1)\end{array}$ & $\begin{array}{c}121.5 \\
(21.5) \\
(1)\end{array}$ & 0.61 & $\begin{array}{c}136 \\
(22.1) \\
(1)\end{array}$ & $\begin{array}{c}121.5 \\
(18.8) \\
(2)\end{array}$ & $\begin{array}{c}135.2 \\
(19.3) \\
(1)\end{array}$ & $\begin{array}{c}126.1 \\
(17.1) \\
(2)\end{array}$ & 0.50 & 0.63 \\
\hline $\begin{array}{l}\text { Dyadic Adjustment } \\
\text { (missing) }\end{array}$ & $\begin{array}{l}49.4(12.2) \\
(7)\end{array}$ & $\begin{array}{l}47.9(7.5) \\
\text { (6) }\end{array}$ & $\begin{array}{l}53.2(6.4) \\
\text { (9) }\end{array}$ & $\begin{array}{c}51.0(8.2) \\
(11)\end{array}$ & 0.30 & $\begin{array}{l}54.5(9.2) \\
(6)\end{array}$ & $\begin{array}{c}48.5(6.7) \\
(6)\end{array}$ & $\begin{array}{c}54.7(7.6) \\
(7)\end{array}$ & $\begin{array}{c}51.3(5.5) \\
(4)\end{array}$ & 0.57 & 0.36 \\
\hline
\end{tabular}

Note. Data presented are for the entire sample, including dyads and men with prostate cancer who participated alone. ${ }^{*}=$ Effect Sizes are provided for each man and caregiver, as well as the combined effect size (last column). Clinical significance is based on the combined ES. SD = standard deviation.

The clinical significance threshold was also met for quality of life: mental-Effect Size $=0.38$ and physical-Effect Size $=0.30$. Increases in quality of life-mental equivalent to the minimal clinically important difference was noted for $33.3 \%$ of patients, but only $22.2 \%$ of caregivers (vs. control patients $26.1 \%$ and caregivers $16.7 \%$, Odds Ratio $=1.42$ ). For quality of life-physical, twice as many caregivers in TEMPO improved (33.3\% caregivers) than in the control group $(16.5 \%)$. This trend was not observed for patients (TEMPO $=23.8 \%$, control $30.4 \%$ ). In the exit interview, dyads emphasized that many patients were already active, but TEMPO engaged more caregivers to be physically active.

A trend is noted in the separate effect sizes for patients and caregivers, whereby caregivers seemed to benefit more from TEMPO than patients on mental health outcomes. When removing the men who participated in TEMPO alone (i.e., leaving those who completed TEMPO as a dyad), effect sizes for the primary outcomes were even higher: anxiety effect size $=0.38$, quality of life-mental effect size $=0.48$, and quality of life-physical effect size $=0.33$ (see Supplementary Material S2). Given the small samples, these results are considered exploratory only. In the exit interviews, dyads referred to coaching each other, to help achieve their goals, which might explain this trend.

\subsection{Secondary Outcomes}

Clinically significant changes were noted for most of the secondary outcomes (see Table 4).

\section{Discussion}

It is now recognized that cancer has a physical and mental impact not only on the individuals diagnosed [2], but also on those who provide them with support-their family caregivers $[15,18]$. With this recognition, an increasing number of patient-caregiver interventions (or dyadic interventions) have been developed [20,79]. However, within a resource-constrained health care environment (even more so with the pandemic), the intense face-to-face format of these interventions is such that they are rarely translated to routine care. We also know that only $10-15 \%$ of patients require high intensity, specialized care to help them cope with cancer challenges [80]. This means that most individuals (and their caregivers) benefit from low-intensity interventions, such as web-based self-management interventions. A Delphi survey [81] found that $86 \%$ of managers wanted more research on cost-effective formats for caregiver interventions, including using online formats.

TEMPO is the first dyadic Tailored, wEb-based psychosocial and physical activity self-Management PrOgram for men with prostate cancer and their caregivers. As a dyadic intervention, TEMPO addresses the needs of men with prostate cancer and their caregivers as well as the relational aspect of coping with cancer challenges [82]. Our initial qualitative acceptability $(n=18)$ study emphasized dyads' satisfaction with the platform and their 
perceived benefits of using TEMPO (e.g., increased self-management) [37,38]. The present pilot documented key benchmarks for feasibility, acceptability, and clinical significance in preparation for a larger trial. Overall, this pilot was successful, and the four key findings are: (a) dyads favored modules over the factsheets in the health library, (b) a dyadic intervention focused on both psychosocial needs and health behavior was acceptable and might lead to better adherence and outcomes, (c) caregivers seem to benefit more than the men with prostate cancer on mental health outcomes, and (d) more tailoring of TEMPO is required.

The first key finding is that dyads found the process-focused behavior change modules more useful than the content-based factsheets. Typical web-based interventions define a series of five or more modules based on pre-determined content, with each module released sequentially $[29,30,83]$. According to the extensive literature pertaining to patients' and caregivers' unmet needs, they generally experience 1-2 dire needs [84-87]. With typical web-based interventions, this means patients and caregivers potentially have to wait weeks for the release of the most-needed module(s). This in turn might explain some of the high attrition and low adherence observed for web-based interventions. TEMPO was designed differently-it is not content-based, but rather focused on the behavior change process inherent in learning new coping and self-management skills, and this seemed particularly useful for participants and appeared to be the reason for achieving the clinical significance benchmarks for most outcomes.

The next key finding was that a dyadic intervention focused on both psychosocial needs and physical activity was acceptable. However, it should be noted that the focus on physical activity was more appreciated than the one on psychosocial needs. This is consistent with Jacobsen et al. [88] who found that a combined stress management and home-based physical activity intervention was more efficacious among patients with cancer than either intervention alone. TEMPO is the first dyadic intervention with such a dual focus, challenging the almost exclusive focus on psychosocial needs of current dyadic and caregiver interventions [20]. A systematic review of 14 trials (mostly among caregivers of patient with dementia) concluded that physical activity can increase caregivers' well-being, quality of life, and self-efficacy [89]. However, many of these studies targeted the caregiver alone, missing an opportunity to involve the patient-caregiver dyad to positively impact adherence and behavior change [90]. Since this review, three dyadic physical activity interventions were published (ballroom dancing [91], dyadic yoga [92], and dyadic strength training [93]), with benefits on patients' and caregivers' physical activity levels and quality of life. Only one study targeted men with prostate cancer and their caregivers [93], all used a face-to-face format, and none offered comprehensive content to address psychosocial needs. Of note, the consent rate in the present pilot exceeded those in these studies [91,93], which might support the more flexible approach taken by TEMPO.

Adherence to web-based interventions remains a challenge. Low adherence means that individuals might not be exposed to the intervention enough to change outcomes [94]. In the present pilot, only $19 \%$ of participants did not complete any modules, much lower than the two-thirds reported in a recent systematic review by Beatty et al. [94]. The literature generally indicates that participants complete on average half of the modules offered [94-100]. In the present study, 1.7 modules on average were completed, but this is using the stringent criterion that all pages of a module were viewed and at least 15 min was spent on TEMPO. Definitions of module completion vary widely across studies, and if we use a less stringent criterion such as $50 \%$ of pages viewed and spending at least $5 \mathrm{~min}$ on the module, the number of modules completed increases to 2.5. However, focusing simply on number of modules completed assumes that all modules are equally important. We did not define a priori which modules are the most important ones for a therapeutic effect but based on the interviews these would be Modules 1 and 2 where needs assessment and goal setting were the active components. These two modules were completed by $60 \%$ and $40 \%$, respectively, of participants. Using less stringent criteria, completion was as high as $70-80 \%$. Men with prostate cancer and the caregivers did report coaching or guiding each other through the intervention, and this form of guidance might increase adherence [94]. 
The effect sizes mostly met our a priori benchmarks. In examining the individual effect sizes, caregivers seemed to benefit more than the men with prostate cancer on mental health outcomes. Although this is a pilot and such a conclusion needs to be taken with caution, our observation is consistent with other studies finding that caregivers benefit more than patients from a dyadic intervention [101]. This might be because caregivers have access to few supportive care services. Other explanations might be that caregivers felt some relief in their burden by knowing patients are getting support as well (less pressure to provide all the support) or women might feel more comfortable disclosing their anxiety and depression symptoms.

TEMPO was designed so that dyads could tailor content based on the needs assessment in Module 1. However, dyads did not perceive this as tailoring, rather interview data indicated that tailoring needed to occur based on stage of disease, time since diagnosis, fitness level, and the type of support systems they had access to. Northouse et al. [29] developed a tailored, web-based psycho-education interventions for patients with cancer and their caregivers, and in this intervention, tailored messaging was developed based on cancer type and dyad relationship as well as level of dyadic communication. A similar strategy could be used in future iterations of TEMPO to integrate the suggestions from participants.

\subsection{Strengths and Limitations}

This pilot study tested TEMPO using a rigorous design, enrolled dyads across different settings, and demonstrated the acceptability of a process-based (as opposed to content) intervention. Another strength is the clear a priori benchmarks that were established and mostly met. A potential bias relating to participants who declined because they had no time is acknowledged and identifies a marketing strategy that needs to be developed. Another limitation is that the reliance on online, text-based content for the modules might exclude some patient sub-groups (e.g., those with low-literacy levels, those who do not have access to the internet, those who do not speak English or French), and diversifying the modes of delivery (e.g., more videos, images) will be considered in future developments.

\subsection{Implications}

TEMPO may be an important tool to support men with prostate cancer and caregivers facing the challenges of prostate cancer that could be integrated in a stepped care approach to supportive care, and eventually adapted to other cancer types. This pilot also emphasized the importance of supporting the behavior change process inherent in self-management (beyond passive dissemination of information). Some improvements will include further tailoring TEMPO to the men's stage of disease, time since diagnosis, fitness level, and the type of support available. In addition, in the larger trial, dyads need to be approached closer to the time of diagnosis.

\section{Conclusions}

This pilot study was successful, and the acceptability, feasibility, and clinical significance of TEMPO was supported. The general positive outcomes might be due to several factors. First, the development of TEMPO has been an iterative process, with continuous input from men with prostate cancer and their caregivers. Second, TEMPO guides dyads through the behavior change process inherent in self-management, setting it apart from many other web-based interventions. Third, the dyadic format might be harnessing the synergistic effect of supporting both patients and caregivers in meeting their needs (which seems to particularly beneficial for caregivers). Even if the results of this pilot are promising, a larger trial needs to be conducted prior to concluding that TEMPO is efficacious.

Supplementary Materials: The following are available online at https: / www.mdpi.com/article/ 10.3390/curroncol29020067/s1, Supplementary Material S1: TEMPO feedback survey results and Supplementary Material S2: Analysis of primary outcomes only for the dyads. 
Author Contributions: Conceptualization: S.D.L., L.R.D., S.N.C.-R., C.S.H., A.K., J.E., P.S.-C., S.P.; Methods: S.D.L., L.R.D., S.N.C.-R., C.S.H., A.K., M.D.R., J.E., M.B.K., P.S.-C., C.S., L.W., S.P., C.I.; Analysis: E.B., E.L., S.P., P.S.-C., H.M.-C.; Writing-Original Draft Preparation: S.D.L., L.R.D., L.H., E.L., M.D.R., E.B.; Writing—Review \& Editing, S.N.C.-R., C.S.H., A.K., J.E., M.B.K., C.S., L.W., P.S.-C., H.M.-C., S.P., C.I. Project Administration: M.D.R., C.S., M.B.K., C.I.; Funding Acquisition, S.D.L., L.R.D., S.N.C.-R., C.S.H., A.K., J.E., P.S.-C., S.P. All authors have read and agreed to the published version of the manuscript.

Funding: This research was funded by Prostate Cancer Canada-The Canadian Cancer Society. Sylvie Lambert is supported by a Canadian Research Chair (Tier 2).

Institutional Review Board Statement: The study was conducted according to the guidelines of the Declaration of Helsinki, and approved by the Ethics Committee of the McGill University Health Centre (protocol code MP-CUSM-15-179 and 18 August 2015).

Informed Consent Statement: Informed consent was obtained from all subjects involved in the study.

Data Availability Statement: The data presented in this study are available on request from the corresponding author.

Acknowledgments: We would like to think all clinicians who have helped us recruit participants for this study as well as the men and their caregivers who took the time to use TEMPO and complete evaluation measures.

Conflicts of Interest: The authors declare no conflict of interest. The funders had no role in the design, execution, interpretation, or writing of the study.

\section{References}

1. Canadian Cancer Society's Advisory Committee on Cancer Statistics. Canadian Cancer Statistics 2016; Canadian Cancer Society: Toronto, ON, Canada, 2016.

2. Msaouel, P.; Gralla, R.J.; Jones, R.A.; Hollen, P.J. Key issues affecting quality of life and patient-reported outcomes in prostate cancer: An analysis conducted in 2128 patients with initial psychometric assessment of the prostate cancer symptom scale (PCSS). BMJ Support. Palliat. Care 2017, 7, 308-315. [CrossRef]

3. Regan, T.W.; Lambert, S.D.; Kelly, B.; McElduff, P.; Girgis, A.; Kayser, K.; Turner, J. Cross-sectional relationships between dyadic coping and anxiety, depression, and relationship satisfaction for patients with prostate cancer and their spouses. Patient Educ. Couns. 2014, 96, 120-127. [CrossRef] [PubMed]

4. Isbarn, H.; Boccon-Gibod, L.; Carroll, P.R.; Montorsi, F.; Schulman, C.; Smith, M.R.; Sternberg, C.N.; Studer, U.E. Androgen Deprivation Therapy for the Treatment of Prostate Cancer: Consider Both Benefits and Risks. Eur. Urol. 2009, 55, 62-75. [CrossRef] [PubMed]

5. Hsiao, C.-P.; Loescher, L.J.; Moore, I.M.K. Symptoms and Symptom Distress in Localized Prostate Cancer. Cancer Nurs. 2007, 30, E19-E32. [CrossRef] [PubMed]

6. Casey, R.G.; Corcoran, N.M.; Goldenberg, S.L. Quality of life issues in men undergoing androgen deprivation therapy: A review. Asian J. Androl. 2012, 14, 226-231. [CrossRef] [PubMed]

7. Chipperfield, K.; Fletcher, J.; Millar, J.; Brooker, J.; Smith, R.; Frydenberg, M.; Burney, S. Predictors of depression, anxiety and quality of life in patients with prostate cancer receiving androgen deprivation therapy. Psycho-Oncology 2013, 22, $2169-2176$. [CrossRef] [PubMed]

8. Donovan, K.A.; Walker, L.M.; Wassersug, R.J.; Thompson, L.M.A.; Robinson, J.W. Psychological effects of androgen-deprivation therapy on men with prostate cancer and their partners. Cancer 2015, 121, 4286-4299. [CrossRef] [PubMed]

9. Mazariego, C.G.; Egger, S.; King, M.T.; Juraskova, I.; Woo, H.; Berry, M.; Armstrong, B.K.; Smith, D.P. Fifteen year quality of life outcomes in men with localised prostate cancer: Population based Australian prospective study. BMJ 2020, 371, m3503. [CrossRef] [PubMed]

10. Northouse, L.L.; McCorkle, R. Spouse Caregivers of Cancer Patients. In Psycho-Oncology; Oxford University Press: New York, NY, USA, 2015.

11. Lambert, S.D.; Levesque, J.V.; Girgis, A. The Impact of Cancer and Chronic Conditions on Caregivers and Family Members. In Cancer and Chronic Conditions: Addressing the Problem of Multimorbidity in Cancer Patients and Survivors; Koczwara, B., Ed.; Springer: Singapore, 2016; pp. 159-202.

12. Sinha, M. Spotlight on Canadians: Results from the General Social Survey. Portrait of Caregivers, 2012; Minister of Industry Canada: Ottawa, ON, Canada, 2013; pp. 1-21. Available online: https://www150.statcan.gc.ca/n1/en/pub/89-652-x/89-652-x2013001 -eng.pdf?st=Fn_g-Lbt (accessed on 15 December 2014). 
13. McMullen, C.K.; Schneider, J.; Altschuler, A.; Grant, M.; Hornbrook, M.C.; Liljestrand, P.; Krouse, R.S. Caregivers as healthcare managers: Health management activities, needs, and caregiving relationships for colorectal cancer survivors with ostomies. Support. Care Cancer 2014, 22, 2401-2408. [CrossRef]

14. Ellis, J.; Wagland, R.; Tishelman, C.; Williams, M.L.; Bailey, C.D.; Haines, J.; Caress, A.; Lorigan, P.; Smith, J.A.; Booton, R.; et al. Considerations in Developing and Delivering a Nonpharmacological Intervention for Symptom Management in Lung Cancer: The Views of Patients and Informal Caregivers. J. Pain Symptom Manag. 2012, 44, 831-842. [CrossRef]

15. Lambert, S.D.; Girgis, A.; Lecathelinais, C.; Stacey, F. Walking a mile in their shoes: Anxiety and depression among partners and caregivers of cancer survivors at 6 and 12 months post-diagnosis. Support. Care Cancer 2013, 21, 75-85. [CrossRef] [PubMed]

16. Girgis, A.; Lambert, S. Caregivers of cancer survivors: The state of the field. Cancer Forum 2009, 33, 167-171.

17. Stenberg, U.; Ruland, C.M.; Miaskowski, C. Review of the literature on the effects of caring for a patient with cancer. PsychoOncology 2009, 19, 1013-1025. [CrossRef] [PubMed]

18. Lambert, S.D.; Girgis, A.; Descallar, J.; Levesque, J.V.; Jones, B.L. Partners' and Caregivers' Psychological and Physical Adjustment to Cancer within the First Five Years Post Survivor Diagnosis. Psycho-Oncology 2014, $23,77$.

19. Reinhard, S.C.; Given, B.; Petlick, N.H.; Bemis, A.; Hughes, R.G. Supporting Family Caregivers in Providing Care. In Patient Safety and Quality: An Evidence-Based Handbook for Nurses; Hughes, R.G., Ed.; Agency for Healthcare Research and Quality: Rockville, MD, USA, 2008.

20. Regan, T.W.; Lambert, S.D.; Girgis, A.; Kelly, B.; Kayser, K.; Turner, J. Do Couple-Based Interventions Make a Difference for Couples Affected by Cancer?: A Systematic Review. BMC Cancer 2012, 12, 279. [CrossRef] [PubMed]

21. Jones, M.C.; MacGillivray, S.; Kroll, T.; Zohoor, A.R.; Connaghan, J. A thematic analysis of the conceptualisation of self-care, self-management and self-management support in the long-term conditions management literature. J. Nurs. Health Chronic Illn. 2011, 3, 174-185. [CrossRef]

22. Institute of Medicine; Board on Health Care Services; Committee on the Crossing the Quality Chasm: Next Steps Toward a New Health Care System; Adams, K.; Greiner, A.C.; Corrigan, J.M. (Eds.) The 1st Annual Crossing the Quality Chasm Summit: A Focus on Communities: Report of a Summit; The National Academies Press: Washington, DC, USA, 2004.

23. Boekaerts, M.; Pintrich, P.R.; Zeider, M. Handbook of Self-Regulation; Academic Press: San Diego, CA, USA, 2000.

24. McCorkle, R.; Ercolano, E.; Lazenby, M.; Schulman-Green, D.; Schilling, L.S.; Lorig, K.; Wagner, E.H. Self-management: Enabling and empowering patients living with cancer as a chronic illness. CA: A Cancer J. Clin. 2011, 61, 50-62. [CrossRef]

25. Haase, K.R.; Sattar, S.; Hall, S.; McLean, B.; Wills, A.; Gray, M.; Kenis, C.; Donison, V.; Howell, D.; Puts, M. Systematic review of self-management interventions for older adults with cancer. Psycho-Oncology 2021, 30, 989-1008. [CrossRef]

26. Howell, D.; Harth, T.; Brown, J.; Bennett, C.; Boyko, S. Self-management education interventions for patients with cancer: A systematic review. Support. Care Cancer 2017, 25, 1323-1355. [CrossRef]

27. Northouse, L.; Williams, A.-L.; Given, B.; McCorkle, R. Psychosocial Care for Family Caregivers of Patients with Cancer. J. Clin. Oncol. 2012, 30, 1227-1234. [CrossRef]

28. Beatty, L.; Lambert, S. A systematic review of internet-based self-help therapeutic interventions to improve distress and diseasecontrol among adults with chronic health conditions. Clin. Psychol. Rev. 2013, 33, 609-622. [CrossRef]

29. Northouse, L.; Schafenacker, A.; Barr, K.L.C.; Katapodi, M.; Yoon, H.; Brittain, K.; Song, L.; Ronis, D.L.; An, L. A Tailored Web-Based Psychoeducational Intervention for Cancer Patients and Their Family Caregivers. Cancer Nurs. 2014, 37, 321-330. [CrossRef] [PubMed]

30. Badr, H.; Lipnick, D.; Diefenbach, M.A.; Posner, M.R.; Kotz, T.; Miles, B.A.; Genden, E.M. Development and usability testing of a web-based self-management intervention for oral cancer survivors and their family caregivers. Eur. J. Cancer Care 2015, 25, 806-821. [CrossRef] [PubMed]

31. Lazarus, R.S.; Folkman, S. Stress, Appraisal, and Coping; Springer: New York, NY, USA, 1984.

32. Stanton, A.L.; Danoff-Burg, S.; Huggins, M.E. The first year after breast cancer diagnosis: Hope and coping strategies as predictors of adjustment. Psycho-Oncology 2002, 11, 93-102. [CrossRef] [PubMed]

33. Bodenmann, G. A systemic-transactional conceptualization of stress and coping in couples. Swiss J. Psychol. 1995, 54, 34-49.

34. Regan, T.W.; Lambert, S.; Kelly, B.; Falconier, M.; Kissane, D.; Levesque, J.V. Couples coping with cancer: Exploration of theoretical frameworks from dyadic studies. Psycho-Oncology 2015, 24, 1605-1617. [CrossRef]

35. Bandura, A. Social Foundations of Thought and Action: A Social Cognitive Theory; Prentice-Hall Inc.: Englewood Cliffs, NJ, USA, 1986; Volume xiii, p. 617.

36. Hoffmann, T.C.; Glasziou, P.P.; Boutron, I.; Milne, R.; Perera, R.; Moher, D.; Altman, D.G.; Barbour, V.; Macdonald, H.; Johnston, M.; et al. Better reporting of interventions: Template for intervention description and replication (TIDieR) checklist and guide. BMJ 2014, 348, g1687. [CrossRef]

37. Lambert, S.D.; Duncan, L.R.; Ellis, J.; Schaffler, J.L.; Loban, E.; Robinson, J.W.; Culos-Reed, N.; Matthew, A.; Clayberg, K.; Mina, D.S.; et al. Acceptability and Usefulness of a Dyadic, Tailored, Web-Based, Psychosocial and Physical Activity Self-Management Program (TEMPO): A Qualitative Study. J. Clin. Med. 2020, 9, 3284. [CrossRef]

38. Hallward, L.; Chemtob, K.; Lambert, S.D.; Duncan, L.R. Prostate Cancer Survivors' and Caregivers' Experiences Using Behavior Change Techniques during a Web-Based Self-Management and Physical Activity Program: A Qualitative Study. J. Clin. Med. 2020, 9, 3244. [CrossRef] 
39. Lambert, S.D.; Duncan, L.R.; Ellis, J.; Robinson, J.W.; Sears, C.; Culos-Reed, N.; Matthew, A.; De Raad, M.; Schaffler, J.L.; Mina, D.S.; et al. A study protocol for a multicenter randomized pilot trial of a dyadic, tailored, web-based, psychosocial, and physical activity self-management program (TEMPO) for men with prostate cancer and their caregivers. Pilot Feasibility Stud. $2021,7,78$. [CrossRef]

40. Moher, D.; Hopewell, S.; Schulz, K.F.; Montori, V.; Gøtzsche, P.C.; Devereaux, P.J.; Elbourne, D.; Egger, M.; Altman, D.G. CONSORT 2010 Explanation and Elaboration: Updated guidelines for reporting parallel group randomised trials. BMJ 2010, 340, c869. [CrossRef] [PubMed]

41. Thabane, L.; Hopewell, S.; Lancaster, G.; Bond, C.M.; Coleman, C.L.; Campbell, M.J.; Eldridge, S. Methods and processes for development of a CONSORT extension for reporting pilot randomized controlled trials. Pilot Feasibility Stud. 2016,2 , 25. [CrossRef] [PubMed]

42. Zigmond, A.S.; Snaith, R.P. The hospital anxiety and depression scale. Acta Psychiatr. Scand. 1983, 67, 361-370. [CrossRef]

43. Bjelland, I.; Dahl, A.A.; Haug, T.T.; Neckelmann, D. The validity of the Hospital Anxiety and Depression Scale. An updated literature review. J. Psychosom. Res. 2002, 52, 69-77. [CrossRef]

44. Roberge, P.; Dore, I.; Menear, M.; Chartrand, E.; Ciampi, A.; Duhoux, A.; Fournier, L. A psychometric evaluation of the French Canadian version of the Hospital Anxiety and Depression Scale in a large primary care population. J. Affect. Disord. 2013, 147, 171-179. [CrossRef] [PubMed]

45. Kosinski, M.; Ware, J.E.; Turner-Bowker, D.M.; Gandek, B. User's Manual for the SF-12v2 Health Survey: With a Supplement Documenting the SF-12 ${ }^{\circledR}$ Health Survey; QualityMetric Incorporated: Lincoln, RI, USA, 2007.

46. Gandek, B.; Ware, J.E.; Aaronson, N.K.; Apolone, G.; Bjorner, J.B.; Brazier, J.E.; Bullinger, M.; Kaasa, S.; Leplege, A.; Prieto, L.; et al. Cross-Validation of Item Selection and Scoring for the SF-12 Health Survey in Nine Countries: Results from the IQOLA Project. International Quality of Life Assessment. J. Clin. Epidemiol. 1998, 51, 1171-1178. [CrossRef]

47. Busija, L.; Pausenberger, E.; Haines, T.; Haymes, S.; Buchbinder, R.; Osborne, R. Adult measures of general health and healthrelated quality of life: Medical Outcomes Study Short Form 36-Item (SF-36) and Short Form 12-Item (SF-12) Health Surveys, Nottingham Health Profile (NHP), Sickness Impact Profile (SIP), Medical Outcomes Study Sh. Arthritis Care Res. 2011, 63, S383-S412. [CrossRef]

48. Cohen, S.; Kamarck, T.; Mermelstein, R. A Global Measure of Perceived Stress. J. Health Soc. Behav. 1983, 24, 385-396. [CrossRef]

49. Lee, E.-H. Review of the Psychometric Evidence of the Perceived Stress Scale. Asian Nurs. Res. 2012, 6, 121-127. [CrossRef]

50. Lesage, F.-X.; Berjot, S.; Deschamps, F. Psychometric properties of the French versions of the Perceived Stress Scale. Int. J. Occup. Med. Environ. Health 2012, 25, 178-184. [CrossRef]

51. Osborne, R.H.; Elsworth, G.R.; Whitfield, K. The Health Education Impact Questionnaire (heiQ): An outcomes and evaluation measure for patient education and self-management interventions for people with chronic conditions. Patient Educ. Couns. 2007, 66, 192-201. [CrossRef] [PubMed]

52. Maunsell, E.; Lauzier, S.; Brunet, J.; Pelletier, S.; Osborne, R.H.; Campbell, H.S. Health-Related Empowerment in Cancer: Validity of Scales from the Health Education Impact Questionnaire. Cancer 2014, 120, 3228-3236. [CrossRef] [PubMed]

53. Bélanger, A.; Hudon, C.; Fortin, M.; Amirall, J.; Bouhali, T.; Chouinard, M.-C. Validation of a French-language version of the health education impact Questionnaire (heiQ) among chronic disease patients seen in primary care: A cross-sectional study. Health Qual. Life Outcomes 2015, 13, 64. [CrossRef] [PubMed]

54. Osborne, R.H.; Batterham, R.W.; Elsworth, G.R.; Hawkins, M.; Buchbinder, R. The grounded psychometric development and initial validation of the Health Literacy Questionnaire (HLQ). BMC Public Health 2013, 13, 658. [CrossRef]

55. Debussche, X.; Lenclume, V.; Balcou-Debussche, M.; Alakian, D.; Sokolowsky, C.; Ballet, D.; Elsworth, G.R.; Osborne, R.; Huiart, L. Characterisation of health literacy strengths and weaknesses among people at metabolic and cardiovascular risk: Validity testing of the Health Literacy Questionnaire. SAGE Open Med. 2018, 6, 2050312118801250. [CrossRef]

56. Craig, C.L.; Marshall, A.L.; Sjöström, M.; Bauman, A.E.; Booth, M.L.; Ainsworth, B.E.; Pratt, M.; Ekelund, U.; Yngve, A.; Sallis, J.F.; et al. International Physical Activity Questionnaire: 12-Country Reliability and Validity. Med. Sci. Sports Exerc. 2003, 35, 1381-1395. [CrossRef]

57. Ajzen, I. Constructing a TpB Questionnaire: Conceptual and Methodological Considerations. 2002. Available online: https: / / citeseerx.ist.psu.edu/viewdoc/download?doi=10.1.1.601.956\&rep=rep1\&type=pdf (accessed on 17 March 2019).

58. Rodgers, W.M.; Wilson, P.M.; Hall, C.R.; Fraser, S.N.; Murray, T.C. Evidence for a multidimensional self-efficacy for exercise scale. Res. Q. Exerc. Sport 2008, 79, 222-234. [CrossRef]

59. Bodenmann, G. Dyadisches Coping Inventar: Test Manual [Dyadic Coping Inventory: Test Manual]; Huber: Bern, Switzerland, 2008.

60. Feldman, B.; Broussard, C.A. The Influence of relational factors on men's adjustment to their partners' newly-diagnosed breast cancer. J. Psychosoc. Oncol. 2005, 23, 23-43. [CrossRef]

61. Bodenmann, G.; Arista, L.J.; Walsh, K.J.; Randall, A.K. Dyadic Coping Inventory. In Encyclopedia of Couple and Family Therapy; Lebow, J., Chambers, A., Breunlin, D., Eds.; Springer: Cham, Switzerland, 2018; Available online: https://doi.org/10.1007/978-3319-15877-8_678-1 (accessed on 26 November 2021). [CrossRef]

62. Spanier, G.B. Measuring Dyadic Adjustment: New Scales for Assessing the Quality of Marriage and Similar Dyads. J. Marriage Fam. 1976, 38, 15. [CrossRef]

63. Manne, S.L.; Norton, T.R.; Ostroff, J.S.; Winkel, G.; Fox, K.; Grana, G. Protective buffering and psychological distress among couples coping with breast cancer: The moderating role of relationship satisfaction. J. Fam. Psychol. 2007, 21, 380-388. [CrossRef] 
64. Lambert, S.D.; Girgis, A.; McElduff, P.; Turner, J.; Levesque, J.V.; Kayser, K.; Mihalopoulos, C.; Shih, S.T.F.; Barker, D. A parallelgroup, randomised controlled trial of a multimedia, self-directed, coping skills training intervention for patients with cancer and their partners: Design and rationale. BMJ Open 2013, 3, e003337. [CrossRef] [PubMed]

65. Brooke, J. SUS: A 'Quick and Dirty' Usability Scale. Usability Eval. Ind. 1996, 189, 4-7.

66. Davis, F.D.; Bagozzi, R.P.; Warshaw, P.R. User Acceptance of Computer Technology: A Comparison of Two Theoretical Models. Manag. Sci. 1989, 35, 982-1003. [CrossRef]

67. Davis, F.D. Perceived Usefulness, Perceived Ease of Use, and User Acceptance of Information Technology. MIS Q. 1989, 13, 319-340. [CrossRef]

68. Venkatesh, V.; Morris, M.G.; Davis, G.B.; Davis, F.D. User Acceptance of Information Technology: Toward a Unified View. MIS Q. 2003, 27, 425-478. [CrossRef]

69. SAS Institute Inc. SAS (R) University Edition; SAS Institute Inc.: Cary, NC, USA, 2015.

70. StataCorp. Stata Statistical Software: Release 15; StataCorp LLC.: College Station, TX, USA, 2017.

71. R Core Team. R: A Language and Environment for Statistical Computing; R Core Team: Vienna, Austria, 2020.

72. Cohen, J. A power primer. Psychol. Bull. 1992, 112, 155-159. [CrossRef]

73. Fitzmaurice, G.M.; Laird, N.M.; Ware, J.H. Applied Longitudinal Analysis; John Wiley \& Sons Inc.: Hoboken, NJ, USA, 2014.

74. Hedges, L.V. Effect sizes in nested designs. In The Handbook of Research Synthesis and Meta-Analysis; Cooper, H., Hedges, L.V., Valentine, J.C., Eds.; Russell Sage Foundation: New York, NY, USA, 2009; pp. 337-356.

75. Borenstein, M.; Hedges, L.V.; Higgins, J.P.T.; Rothstein, H.R. Introduction to Meta-Analysis, 1st ed.; John Wiley \& Sons Ltd.: Hoboken, NJ, USA, 2009.

76. Puhan, M.A.; Frey, M.; Büchi, S.; Schünemann, H.J. The minimal important difference of the hospital anxiety and depression scale in patients with chronic obstructive pulmonary disease. Health Qual. Life Outcomes 2008, 6, 46. [CrossRef]

77. Díaz-Arribas, M.J.; Fernández-Serrano, M.; Royuela, A.; Kovacs, F.M.; Gallego-Izquierdo, T.; San, M.-P.O.; Llorca-Palomera, R.; Pardo-Hervás, P.; Martín-Pariente, O.S. Minimal Clinically Important Difference in Quality of Life for Patients with Low Back Pain. Spine 2017, 42, 1908-1916. [CrossRef]

78. QSR International Pty Ltd. NVivo (Version 12). 2018. Available online: https://www.qsrinternational.com/nvivo-qualitativedata-analysis-software/home (accessed on 26 November 2021).

79. Northouse, L.L.; Katapodi, M.C.; Song, L.; Zhang, L.; Mood, D.W. Interventions with Family Caregivers of Cancer Patients: Meta-Analysis of Randomized Trials. CA A Cancer J. Clin. 2010, 60, 317-339. [CrossRef]

80. Fitch, M. Supportive care framework. Can. Oncol. Nurs. J. 2015, 18, 9. [CrossRef]

81. Lambert, S.D.; Brahim, L.O.; Morrison, M.; Girgis, A.; Yaffe, M.; Belzile, E.; Clayberg, K.; Robinson, J.; Thorne, S.; Bottorff, J.L.; et al. Priorities for caregiver research in cancer care: An international Delphi survey of caregivers, clinicians, managers, and researchers. Support. Care Cancer 2018, 27, 805-817. [CrossRef]

82. Thompson, T.; Ketcher, D.; Gray, T.F.; Kent, E.E. The Dyadic Cancer Outcomes Framework: A general framework of the effects of cancer on patients and informal caregivers. Soc. Sci. Med. 2021, 287, 114357. [CrossRef] [PubMed]

83. Beatty, L.; Kemp, E.; Coll, J.R.; Turner, J.; Butow, P.; Milne, D.; Yates, P.; Lambert, S.; Wootten, A.; Yip, D.; et al. Finding My Way: Results of a multicentre RCT evaluating a web-based self-guided psychosocial intervention for newly diagnosed cancer survivors. Support. Care Cancer 2018, 27, 2533-2544. [CrossRef] [PubMed]

84. Girgis, A.; Lambert, S.D.; McElduff, P.; Bonevski, B.; Lecathelinais, C.; Boyes, A.; Stacey, F. Some things change, some things stay the same: A longitudinal analysis of cancer caregivers' unmet supportive care needs. Psycho-Oncology 2013, 22, 1557-1564 [CrossRef] [PubMed]

85. Lambert, S.D.; Girgis, A. Unmet supportive care needs among informal caregivers of patients with cancer: Opportunities and challenges in informing the development of interventions. Asia-Pacific J. Oncol. Nurs. 2017, 4, 136-139. [CrossRef]

86. Lambert, S.D.; Hulbert-Williams, N.; Belzile, E.; Ciampi, A.; Girgis, A. Beyond using composite measures to analyze the effect of unmet supportive care needs on caregivers' anxiety and depression. Psycho-Oncology 2018, 27, 1572-1579. [CrossRef]

87. Harrison, J.D.; Young, J.M.; Price, M.A.; Butow, P.N.; Solomon, M. What are the unmet supportive care needs of people with cancer? A systematic review. Support. Care Cancer 2009, 17, 1117-1128. [CrossRef]

88. Jacobsen, P.B.; Phillips, K.M.; Jim, H.S.L.; Small, B.; Faul, L.A.; Meade, C.D.; Thompson, L.; Williams, C.C., Jr.; Loftus, L.S.; Fishman, M.; et al. Effects of self-directed stress management training and home-based exercise on quality of life in cancer patients receiving chemotherapy: A randomized controlled trial. Psycho-Oncology 2012, 22, 1229-1235. [CrossRef]

89. Lambert, S.D.; Duncan, L.R.; Kapellas, S.; Bruson, A.-M.; Myrand, M.; Santa Mina, D.; Culos-Reed, N.; Lambrou, A. A descriptive systematic review of physical activity interventions for caregivers: Effects on caregivers' and care recipients' psychosocial outcomes, physical activity levels, and physical health. Ann. Behav. Med. 2016, 50, 907-919. [CrossRef]

90. Park, C.L.; Gaffey, A.E. Relationships between psychosocial factors and health behavior change in cancer survivors: An integrative review. Ann. Behav. Med. 2007, 34, 115-134. [CrossRef]

91. Pisu, M.; Demark-Wahnefried, W.; Kenzik, K.M.; Oster, R.; Lin, C.P.; Manne, S.; Alvarez, R.; Martin, M.Y. A dance intervention for cancer survivors and their partners (RHYTHM). J. Cancer Surviv. 2017, 11, 350-359. [CrossRef]

92. Milbury, K.; Liao, Z.; Shannon, V.; Mallaiah, S.; Nagarathna, R.; Li, Y.; Yang, C.; Carmack, C.; Bruera, E.; Cohen, L. Dyadic yoga program for patients undergoing thoracic radiotherapy and their family caregivers: Results of a pilot randomized controlled trial. Psycho-Oncology 2019, 28, 615-621. [CrossRef] [PubMed] 
93. Winters-Stone, K.M.; Lyons, K.; Dobek, J.C.; Dieckmann, N.; Bennett, J.A.; Nail, L.M.; Beer, T.M. Benefits of partnered strength training for prostate cancer survivors and spouses: Results from a randomized controlled trial of the Exercising Together project. J. Cancer Surviv. 2015, 10, 633-644. [CrossRef]

94. Beatty, L.; Binnion, C. A Systematic Review of Predictors of, and Reasons for, Adherence to Online Psychological Interventions. Int. J. Behav. Med. 2016, 23, 776-794. [CrossRef]

95. Kenter, R.M.F.; Cuijpers, P.; Beekman, A.; Van Straten, A.; Al-Asadi, A.; Crisp, D. Effectiveness of a Web-Based Guided Self-help Intervention for Outpatients with a Depressive Disorder: Short-term Results From a Randomized Controlled Trial. J. Med. Internet Res. 2016, 18, e80. [CrossRef]

96. Kleiboer, A.; Donker, T.; Seekles, W.; van Straten, A.; Riper, H.; Cuijpers, P. A randomized controlled trial on the role of support in Internet-based problem solving therapy for depression and anxiety. Behav. Res. Ther. 2015, 72, 63-71. [CrossRef]

97. Day, V.; McGrath, P.; Wojtowicz, M. Internet-based guided self-help for university students with anxiety, depression and stress: A randomized controlled clinical trial. Behav. Res. Ther. 2013, 51, 344-351. [CrossRef]

98. Twomey, C.; Reilly, G.O.; Byrne, M.; Bury, M.; White, A.; Kissane, S.; McMahon, A.; Clancy, N. A randomized controlled trial of the computerized CBT programme, MoodGYM, for public mental health service users waiting for interventions. Br. J. Clin. Psychol. 2014, 53, 433-450. [CrossRef] [PubMed]

99. Boß, L.; Lehr, D.; Schaub, M.P.; Castro, R.P.; Riper, H.; Berking, M.; Ebert, D.D. Efficacy of a web-based intervention with and without guidance for employees with risky drinking: Results of a three-arm randomized controlled trial. Addiction 2018, 113, 635-646. [CrossRef]

100. Lintvedt, O.K.; Griffiths, K.M.; Sørensen, K.; Østvik, A.R.; Wang, C.E.A.; Eisemann, M.; Waterloo, K. Evaluating the effectiveness and efficacy of unguided internet-based self-help intervention for the prevention of depression: A randomized controlled trial. Clin. Psychol. Psychother. 2011, 20, 10-27. [CrossRef] [PubMed]

101. Northouse, L.L.; Mood, D.W.; Schafenacker, A.; Montie, J.E.; Sandler, H.M.; Forman, J.D.; Hussain, M.; Pienta, K.; Smith, D.; Kershaw, T. Randomized clinical trial of a family intervention for prostate cancer patients and their spouses. Cancer 2007, 110, 2809-2818. [CrossRef] [PubMed] 